\title{
Immune response to a recombinant capsid protein of striped jack nervous necrosis virus (SJNNV) in turbot Scophthalmus maximus and Atlantic halibut Hippoglossus hippoglossus, and evaluation of a vaccine against SJNNV
}

\author{
Súsanna Húsgarð ${ }^{1, *}$, Sindre Grotmol ${ }^{1}$, Brit K. Hjeltnes ${ }^{1}$, Odd Magne Rødseth², \\ Eirik Biering ${ }^{2}$
}

\footnotetext{
${ }^{1}$ Institute of Marine Research, Department of Aquaculture, PO Box 1870, 5817 Bergen-Nordnes, Norway

${ }^{2}$ Intervet Norbio AS, Thormøhlensgt. 55, 5008 Bergen, Norway
}

\begin{abstract}
Immunisation by intraperitoneal injection of an oil-emulgated recombinant partial capsid protein (rT2) from striped jack nervous necrosis virus (SJNNV) was performed on adult turbot Scophthalmus maximus and Atlantic halibut Hippoglossus hippoglossus. A specific humoral immune response was recorded in both species, and the levels of rT2-specific antibodies increased markedly in all groups during the $20 \mathrm{wk}$ experiment. A challenge model for SJNNV was established by intramuscular injection of juvenile turbot. The turbot developed viral encephalopathy and retinopathy (VER), also known as viral nervous necrosis (VNN), with cumulative mortality in the range of 25 to $66 \%$, after intramuscular inoculation with SJNNV propagated in the striped snake head cell line (SSN-1). Although neither clinical signs nor mortality were registered, SJNNV was neuroinvasive after bath exposure. The infection after both modes of challenge was verified by means of immunohistochemistry and RT-PCR, and SJNNV was reisolated in cell culture. The results indicate that SJNNV may have entered the central nervous system (CNS) by axonal transport through motor nerves after intramuscular inoculation. A vaccine efficacy test was performed on juvenile turbot, employing oil emulsified rT2 as a test vaccine and intramuscular inoculation of SJNNV. Significant protection was observed when the challenge was performed $10 \mathrm{wk}$ post-vaccination.
\end{abstract}

KEY WORDS: Viral encephalopathy and retinopathy $(\mathrm{VER}) \cdot$ Nodavirus $\cdot$ Challenge model $\cdot$ Recombinant vaccine $\cdot$ Turbot $\cdot$ Atlantic halibut

\section{INTRODUCTION}

Viral encephalopathy and retinopathy (VER), also known as viral nervous necrosis (VNN), affects a number of cultured marine teleost species all over the world (Munday \& Nakai 1997). The disease may cause high mortality particularly in larvae and juveniles, but

*E-mail: susanna.husgard@imr.no has also been recorded in adult stages of some species (Fukuda et al. 1996, Le Breton et al. 1997). Common clinical signs of VER include lack of appetite, changes in pigmentation, hyperinflation of the gas-bladder, hyperreactivity and abnormal swimming behaviour. Gross pathological changes are uncommon while characteristic microscopic lesions include cellular vacuolation and neuronal degeneration in the central nervous system (CNS), the retina and the ganglia of the peripheral nervous system (Munday \& Nakai 1997). 
The causative agents of VER are viruses belonging to the Nodaviridae (Mori et al. 1992, Comps et al. 1994). These viruses are unenveloped and icosahedral, with diameters of approximately $25 \mathrm{~nm}$. Their bipartite genomes consist of single-stranded, positive-sense nonpolyadenylated RNA molecules, encoding the putative RNA-dependent RNA polymerase (RNA1) (Nagai \& Nishizawa 1999) and the capsid protein precursor (RNA2) (Nishizawa et al. 1995).

It has been demonstrated that the broodstock of some teleost species act as reservoirs of nodavirus by shedding viruses through gonadal fluids and infecting offspring (Mushiake et al. 1994, Yoshimizu et al. 1997). Prophylaxis of VER in striped jack Pseudocaranx dentex, barfin flounder Verasper moseri and Japanese flounder Paralychthys olivaceus has been attempted through prevention of vertical transmission by selection of non-carrier spawners identified by RT-PCR on gonadal fluids (Mushiake et al. 1994) or by serodiagnostic methods (Mushiake et al. 1993, Yoshimizu et al. 1997). Although prevention of the disease during larval and juvenile stages may be possible through broodstock management and disinfection of hatchery water, nodavirus in the environment may infect the fish when they are transferred to on-growing sites. Particularly in species whose adult fish are susceptible to VER, additional means of controlling the disease, such as vaccination, may prove to be useful. Vaccines based on recombinant viral structural proteins have already been developed for some other fish viruses, i.e. infectious pancreatic necrosis virus (Knappskog et al. 1999), viral haemorrhagic septicaemia virus (Lorenzen \& Olesen 1997) and infectious hematopoietic necrosis virus (Leong \& Fryer 1993). In addition, Nakai et al. (1995) showed that injecting striped jack with a recombinant capsid protein from striped jack nervous necrosis virus (SJNNV) expressed in E. coli elicited the production of virus-neutralising antibodies. However, this study was performed on a relatively small number of fish (5 in each group), and challenge was not performed to test the efficacy of the vaccine preparation.

VER strikes both the turbot Scophthalmus maximus (Bloch et al. 1991) and the Atlantic halibut Hippoglossus hippoglossus (Grotmol et al. 1997) at sizes large enough to vaccinate. Therefore, both species are appropriate candidates for infection trials and tests of vaccine efficacy. The present study was conducted with a 3-fold purpose in mind. First, we wanted to test whether a vaccine containing a recombinant partial capsid protein (rT2) of SJNNV as antigen in an oil adjuvant was capable of inducing the production of virusspecific antibodies in adults of the 2 species. The second aim was to establish a challenge model for SJNNV that elicited mortality on immunologically competent juveniles of one of these fish species. Finally, employ- ing such a model, we wished to evaluate an intraperitoneally administrated vaccine containing rT2, using mortality as a measure of vaccine efficacy.

\section{MATERIALS AND METHODS}

Immunisation trials. Fish stock and rearing conditions: Twenty-eight turbot (mean weight $570 \pm 120 \mathrm{~g}$ ) and 28 Atlantic halibut (mean weight $695 \pm 190 \mathrm{~g}$ ) were allowed to adapt for $1 \mathrm{wk}$ before the start of the experiment.

The halibut and turbot were reared in separate aquaria at a salinity of $34.5 \%$ and were fed commercial dry pellets twice daily. The halibut were kept at a temperature of $9^{\circ} \mathrm{C}$ while the turbot were kept at $12^{\circ} \mathrm{C}$. The fish were individually labelled with pit-tags. Prior to vaccination and sampling, the fish were starved for $24 \mathrm{~h}$ and anaesthetised with methomidate $\left(5 \mathrm{mg} \mathrm{l}^{-1}\right.$ seawater).

Vaccine preparation: The T2 region comprises 876 bases of the 1023-base ORF in the capsid protein gene of SJNNV (Nishizawa 1995). The rT2 with a predicted molecular weight of $32 \mathrm{kDa}$ was prepared as described in Grotmol et al. (2000). In short, total RNA was isolated from diseased striped jack larvae using the Trizol reagent (Gibco BRL, Life Technologies Inc., Rockville, Maryland, USA). RT-PCR was performed with the primers 5'-AAACATATGGGATTTGGACGTGCGACCAA-3' and 5'-GCTAAGCTTCACGAGTCAACACGGGTGAAGA-3', and products were cloned into the pCR-Script SK(+) vector using the pCR-Script cloning kit (Stratagene Inc, California, USA). The T2 sequence was exerted with NdeI and Hind III and ligated into the expression vector pET-25b (+) (Novagen, Wisconsin, USA). The resulting plasmid was used to transform $E$. coli (BL21) and clones were cultured in LB medium (1\% Bacto-tryptone, $0.5 \%$ Bacto-yeast extract, $1 \%$ $\mathrm{NaCl}, \mathrm{pH} 7.4$ ) with $50 \mu \mathrm{g} \mathrm{ml} \mathrm{m}^{-1}$ ampicillin. The cells were induced by resuspension in fresh LB medium containing $50 \mu \mathrm{g} \mathrm{ul}^{-1}$ ampicillin and $1 \mathrm{mM}$ isopropylthio-D-galactoside (IPTG). Following incubation at $37^{\circ} \mathrm{C}$ for $3 \mathrm{~h}$, the cells were washed and resuspended in 50 mM Tris-HCL (pH 8.0)/2 mM EDTA solution. After addition of lysozyme and Triton X-100 to $100 \mu \mathrm{g} \mathrm{ml}^{-1}$ and $0.1 \%(\mathrm{v} / \mathrm{v})$ respectively, the cell suspension was incubated at $30^{\circ} \mathrm{C}$ for $15 \mathrm{~min}$ and sonicated until the solution lost its viscosity. The insoluble fraction (inclusion bodies) containing the rT2 protein was washed twice with $50 \mathrm{mM}$ Tris-HCL ( $\mathrm{pH}$ 8.0)/2 mM EDTA solution by centrifugation $\left(12000 \times g, 15 \mathrm{~min}, 4^{\circ} \mathrm{C}\right)$ and resuspended into PBS. As shown by SDS-PAGE, the expressed protein had a molecular weight of approximately 32 kDa (Fig. 1). The rT2 suspension was mixed with a non-mineral oil to a water-in-oil emulsion. 


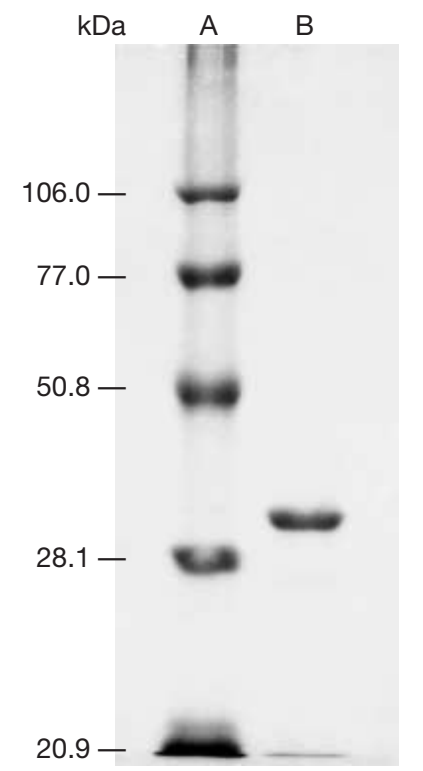

Fig. 1. 12\% SDS-PAGE gel stained with Brilliant Blue $\mathrm{R}$ 250. (A) Molecular weight markers. (B) E. coli expressed T2 protein from SJNNV with expected molecular weight $32 \mathrm{kDa}$
SDS-PAGE: The rT2 was solubilized in reducing sample buffer according to Laemmli (1970) and heated to $95^{\circ} \mathrm{C}$ for $4 \mathrm{~min}$. The gels (4\% stacking gel and $12 \%$ separating gel) were cast in a Miniprotean II Dual Slab Cell system (BioRad, Hercules, California, USA) according to the manufacturer's instructions and run at $200 \mathrm{~V}$ for $40 \mathrm{~min}$. Gels were stained with Brilliant Blue R 250 (Sigma-Aldrich, Steinheim, Germany).

Immunisation and sampling: The fish of both species were divided into 2 groups, each consisting of 14 individuals. They were then immunised by intraperitoneal injection $(0.2 \mathrm{ml})$ of a vaccine prepared as described above, each dose containing $100 \mu \mathrm{g}$ rT2. The fish in 1 group were immunised once, while the fish in the other group were reinjected with the same dose 8 wk later.

At the beginning of the experiment, blood samples $(1.5 \mathrm{ml})$ for ELISA and virus neutralisation assay were obtained from each individual and used as control sera. After immunisation, blood samples were taken from all individuals every fourth week until Week 20.

Challenge trials with turbot. Fish stock and rearing conditions: Two trials (Trial I and Trial II) were performed. In Trial I, 300 turbot juveniles with weights in the range of 1.5 to $3.5 \mathrm{~g}$ (mean $2.5 \mathrm{~g}$ ) were used and in Trial II, 400 turbot with weights of 3.2 to $5.5 \mathrm{~g}$ (mean $4.3 \mathrm{~g}$ ) were employed. The fish were acclimatised for 1 wk and normal feeding behaviour was observed before the start of the experiments. Prior to the experiments 8 fish from each population were screened for nodavirus by RT-PCR. All samples were negative.

The turbot were reared in UV-treated seawater of $34.5 \%$ salinity and fed commercial dry pellets twice daily. Before challenge, the fish were starved for $24 \mathrm{~h}$ and then anaesthetised with methomidate. In Trial I, 2 parallel experiments were performed; one at a temperature of $18^{\circ} \mathrm{C}$ and one at $21^{\circ} \mathrm{C}$. In Trial II, the challenge was performed at $21^{\circ} \mathrm{C}$.

Challenge: In Trial I, 2 parallel groups kept at $18^{\circ} \mathrm{C}$ were challenged by intramuscular injection (IM 18-1 and IM 18-2) and 1 group was kept as a control (C 18). The same experimental set-up was employed at $21^{\circ} \mathrm{C}$ and the groups were designated IM 21-1, IM 21-2 and C 21. Each group of 50 fish was kept in separate tanks. The SJNNV (strain SJ93Nag from striped jack, Nishizawa et al. 1997) used for challenge was propagated in a cell line (SSN-1) derived from the striped snakehead Channa striatus. The turbot were challenged with $100 \mu \mathrm{l}$ SJNNV infected SSN-1 cell culture supernatant $\left(1.0 \times 10^{7} \mathrm{TCID}_{50} \mathrm{ml}^{-1}\right)$. The inoculum was administrated as 2 intramuscular injections of $50 \mu \mathrm{l}, 1$ on each side of the vertebral column. The control groups (C 18, C 21) were mock challenged by injection of supernatant from uninfected SSN-1 cells.

In Trial II both intramuscular inoculation and bath exposure were performed. Each experimental group consisted of 50 turbot. Two parallel groups were challenged by intramuscular injection (IM-1 and IM-2) of SJNNV (titre $6.3 \times 10^{7} \mathrm{TCID}_{50} \mathrm{ml}^{-1}$ ) as described above, and a control group (IMC) was mock challenged by injection of supernatant from uninfected cells. In addition, 2 parallel groups were bath challenged (BC-1 and $\mathrm{BC}-2$ ) for $1 \mathrm{~h}$ in seawater, to which SJNNV to a final titre of $3.7 \times 10^{7} \mathrm{TCID}_{50} \mathrm{ml}^{-1}$ had been added. A control group (BCC) was mock challenged by bath exposure to supernatant from uninfected SSN-1 cells. In both trials clinical signs and mortality were recorded and dead fish were removed twice daily.

Sampling: In both trials, samples of brain, spinal cord and eyes were carefully removed from newly dead fish ( $\mathrm{N}=8$ per group) and used for immunohistochemical examination. Dead fish were frozen at $-80^{\circ} \mathrm{C}$ and heads were used for virus isolation in cell culture ( $\mathrm{N}=5$ per group) while 1 eye and the abdominal organs were used for virus detection by RT-PCR ( $\mathrm{N}=$ 8 per group). In Trial II, additional samples $(\mathrm{N}=5)$ were taken from bath-challenged groups on Day 14 for immunohistochemistry. At the termination of both trial I and II (on Days 28 and 48 post-challenge respectively) brain, spinal cord and eye samples were collected from the survivors and fixed for immunohistochemistry ( $\mathrm{N}=5$ per group) or frozen at $-80^{\circ} \mathrm{C}$ for RT-PCR ( $\mathrm{N}=8$ per group).

Vaccine efficacy test. Fish stock and rearing conditions: For the vaccine efficacy test, 400 turbot juveniles weighing from 1 to $3 \mathrm{~g}$ (mean $1.8 \mathrm{~g}$ ) were allowed to adapt for $3 \mathrm{wk}$ in aquaria with UV-treated seawater at $34.5 \%$ salinity before the start of the experiment. During this period, the temperature was slowly raised from 
12.0 to $16.5^{\circ} \mathrm{C}$. The fish were fed commercial dry pellets twice daily. Prior to the experiment, 8 fish were screened for nodavirus by RT-PCR (all samples were negative).

After vaccination the fish were reared in 2001 aquaria at $16.5^{\circ} \mathrm{C}$. One week prior to challenge, the fish were transferred to $80 \mathrm{l}$ aquaria and the temperature was slowly raised to $21^{\circ} \mathrm{C}$. To reduce stress, the fish were starved for $24 \mathrm{~h}$ and anaesthetised with methomidate before each handling.

Vaccination and challenge: The experimental set-up is shown in Table 1. Prior to vaccination the fish were divided into 4 groups (groups A, B, C and D). Group A was vaccinated by intraperitoneal injection of a vaccine prepared as described above containing $15 \mu \mathrm{g}$ rT2 $\operatorname{dose}^{-1}(10 \mu l)$. Group B was intraperitoneally injected with a control adjuvant formulation without antigen.

Five week post-vaccination, each of the groups (A, B, $C$ and D) was divided into 2 groups. Groups $A_{1}, B_{1}$ and $C_{1}$ were challenged by intramuscular injection of $100 \mu \mathrm{l}$ SSN-1 cell culture supernatant containing SJNNV (titre $6.3 \times 10^{7} \mathrm{TCID}_{50} \mathrm{ml}^{-1}$ ) at $5 \mathrm{wk}$ post-vaccination, whereas groups $\mathrm{A}_{2}, \mathrm{~B}_{2}$ and $\mathrm{C}_{2}$ were challenged at 10 wk post-vaccination. The inoculum was administrated as 2 injections of $50 \mu \mathrm{l}, 1$ on each side of the vertebral column. Groups $\mathrm{D}_{1}$ and $\mathrm{D}_{2}$ were kept as unvaccinated/mock-challenged controls in the challenge trials performed at 5 and $10 \mathrm{wk}$ post-vaccination, respectively. The mock challenge was performed by injection of supernatant from uninfected cells. The behaviour of the fish, including its appetite, was recorded twice daily. All dead fish were removed and recorded twice daily.

Sampling: Eyes and brain were collected from dead fish and tested by RT-PCR ( $\mathrm{N}=5$ per group). The experiments with the $\mathrm{A}_{1}, \mathrm{~B}_{1}$ and $\mathrm{C}_{1}$ groups were terminated 9.5 wk post-vaccination, while the $A_{2}, B_{2}$ and $C_{2}$ groups were terminated 16.5 wk post-vaccination. Eyes, brain, spinal cord and abdominal organs from the survivors in groups $A_{2}, B_{2}, C_{2}$ and $D_{2}$ were sampled

Table 1. Experimental set-up for the vaccine efficacy test (wpv: wk postvaccination)

\begin{tabular}{|c|c|c|c|c|}
\hline \multicolumn{2}{|c|}{ Group (no. of fish) } & \multirow{2}{*}{$\begin{array}{l}\text { Vaccine } \\
\text { rT2 vaccine } \\
\text { rT2 vaccine }\end{array}$} & \multirow{2}{*}{$\begin{array}{c}\text { Challenge } \\
(5 \mathrm{wpv}) \\
\text { Yes }\end{array}$} & \multirow{2}{*}{$\begin{array}{c}\begin{array}{c}\text { Challenge } \\
(10 \text { wpv })\end{array} \\
\text { Yes }\end{array}$} \\
\hline A (100) & $\begin{array}{l}\mathrm{A}_{1}(50) \\
\mathrm{A}_{2}(50)\end{array}$ & & & \\
\hline B (100) & $\begin{array}{l}\mathrm{B}_{1}(50) \\
\mathrm{B}_{2}(50)\end{array}$ & $\begin{array}{l}\text { Control formulation } \\
\text { Control formulation }\end{array}$ & Yes & Yes \\
\hline C (100) & $\begin{array}{l}C_{1}(50) \\
C_{2}(50)\end{array}$ & $\begin{array}{l}\text { Unvaccinated } \\
\text { Unvaccinated }\end{array}$ & Yes & Yes \\
\hline $\mathrm{D}(70)$ & $\begin{array}{l}\mathrm{D}_{1}(35) \\
\mathrm{D}_{2}(35)\end{array}$ & $\begin{array}{l}\text { Unvaccinated } \\
\text { Unvaccinated }\end{array}$ & & \\
\hline
\end{tabular}

for immunohistochemistry on Days 18 and 42 postchallenge ( $\mathrm{N}=5$ per group). Additional samples of eyes for RT-PCR ( $\mathrm{N}=5$ per group) were taken on Days 18 and 42 post-challenge.

Sample analysis. ELISA: The blood samples $(1.5 \mathrm{ml})$ were stored overnight for coagulation and centrifuged $\left(1500 \times g, 5 \mathrm{~min}, 4^{\circ} \mathrm{C}\right)$. The serum from each individual was divided into 3 aliquots and stored at $-80^{\circ} \mathrm{C}$. Detection of rT2-specific antibodies was performed by ELISA according to the following procedure: rT2 was diluted in carbonate-bicarbonate buffer $(15 \mathrm{mM}$ $\mathrm{Na}_{2} \mathrm{CO}_{3}, 35 \mathrm{mM} \mathrm{NaHCO}, \mathrm{pH}$ 9.6) to $10 \mu \mathrm{g} \mathrm{ml}^{-1}$, and 96-well microtitre plates (Nunc, Roskilde, Denmark) were coated with $150 \mu \mathrm{l}$ well ${ }^{-1}$ overnight at $4^{\circ} \mathrm{C}$. The plates were post-coated with $5 \%$ fat-free dried milk in phosphate-buffered saline $(0.1 \mathrm{M}, \mathrm{pH}$ 7.2) containing $0.05 \%$ Tween-20 (PBS-Tween) for $1 \mathrm{~h}$ at $20^{\circ} \mathrm{C}$, washed with PBS-Tween, and stored at $-80^{\circ} \mathrm{C}$ until further processing. All subsequent incubations were carried out in PBS-Tween containing $1 \%$ fat-free dried milk, and PBS-Tween was used for washing between incubations. A dilution series of serum samples, starting at 1:400, was incubated at $4^{\circ} \mathrm{C}$ overnight. The serum samples were followed by a rabbit-anti-halibut or rabbit-anti-turbot immunoglobulin (Ig) serum diluted 1:1000 and finally by a horseradish-peroxidase conjugated goat-anti-rabbit antiserum (BioRad, Hercules, California, USA) diluted 1:3000, both incubated for $1 \mathrm{~h}$ at $20^{\circ} \mathrm{C}$. After washing 6 times with PBS-Tween, the binding was visualised using $100 \mu \mathrm{l} o$-phenylenediamine dihydrochloride (OPD, Sigma, St. Louis, Missouri, USA) solution (0.4 $\mathrm{mg} \mathrm{ml}^{-1}$ OPD in phosphate citrate buffer, $\mathrm{pH}$ 5.0). The reaction was stopped after $10 \mathrm{~min}$ by the addition of $50 \mu \mathrm{l} 2.5 \mathrm{~N} \mathrm{H}_{2} \mathrm{SO}_{4}$. After equilibration for $30 \mathrm{~min}$ at $4^{\circ} \mathrm{C}$, the optical density (OD) was measured at $492 \mathrm{~nm}$ in a Titertec Multiscan SSC spectrophotometer.

Cell culture: SSN-1 cell line (Frerichs et al. 1996) was used for virus propagation and titration. The cells were cultured in Falcon Primaria bottles (Becton Dickinson Labware, Franklin Lakes, New Jersey, USA) at $25^{\circ} \mathrm{C}$ in Leibovitz L-15 medium (Bio-Wittaker, Walkersville, Maryland, USA), supplemented with $10 \%$ foetal bovine serum (Biological Industries, Kibbutz Beit Haemek, Oshrat, Israel), $200 \mathrm{mM}$ L-Glutamine (Bio-Wittaker), $100 \mu \mathrm{g} \mathrm{ll}^{-1}$ Gentamycine sulphate (Bio-Wittaker) and $10 \mathrm{mM}$ HEPES buffer (pH 7) (BioWittaker). For virus production and titration, HEPES was omitted from the medium. For virus titration, the cells were cultured in Falcon Primaria 96-well plates. Titres of the virus suspensions used for challenge were calculated as TCID $_{50}$ according to Reed \& Muench (1938), using 8 parallel wells for each dilution. 
Virus neutralisation assay: Sera from turbot and halibut sampled before immunisation and at the termination, 20 wk after immunisation, were analysed for neutralising activity. Each serum was diluted 2-fold (from 1:100 to 1:51200) in cell culture medium without HEPES. An equal volume of SJNNV (titre $10^{3} \mathrm{TCID}_{50}$ $\mathrm{ml}^{-1}$ ) was added to the diluted sera and the samples were incubated for $1 \mathrm{~h}$ at room temperature. SSN-1 cells were split in to Falcon Primaria 96-well tissue cultures plates $\left(0.1 \mathrm{ml} \mathrm{well}{ }^{-1}\right)$ and $0.1 \mathrm{ml}$ of the serum/ virus samples was added using 4 parallel wells per serum dilution. The cell cultures were examined for cytopathic effect (CPE) 6 d post-infection. The neutralising effect was expressed as the reciprocal value of serum dilution that caused $50 \%$ or higher reduction of the virus titre.

RT-PCR: Frozen samples of eyes or brain were used for RT-PCR detection of SJNNV. Single-step RNA isolation was performed on 50-100 mg tissue homogenates using the Trizol reagent according to the manufacturer's instructions. cDNA synthesis was performed on $1 \mu \mathrm{l}$ RNA using the RNA PCR Core Kit (Perkin Elmer, Branchburg, New Jersey, USA) according to the manufacturer's instructions. The reverse transcription (RT) reaction was primed using random hexanucleotides. The following parameters were used: $10 \mathrm{~min}$ at $22^{\circ} \mathrm{C}, 30 \mathrm{~min}$ at $42^{\circ} \mathrm{C}$, and $10 \mathrm{~min}$ at $95^{\circ} \mathrm{C}$. The total volume of the RT reaction (10 $\mu \mathrm{l})$ was used for PCR amplification of a $426 \mathrm{bp}$ target region (T4) in the gene encoding the capsid protein of SJNNV. Primers F2 and R3 (5'-CGT GTC AGT CAT GTG TCG CT-3' and 5'-CGA GTC AAC ACG GGT GAA GA-3') were used and the reaction was performed according to Nishizawa et al. (1994). The PCR products were analysed on $1.5 \%$ agarose gels (BioRad) in TBE buffer (0.09 M Tris-borate $\mathrm{pH}$ 8.0, 2 mM EDTA). The gels were run for $90 \mathrm{~min}$ at $80 \mathrm{~V}$, stained with ethidium bromide for 30 min and photographed using a Polaroid camera.

Immunohistochemistry: Samples were fixed for at least $15 \mathrm{~h}$ in phosphate-buffered $10 \%$ formalin ( $\mathrm{pH} 7.4$ ), dehydrated through a graded ethanol series and embedded in paraffin wax. Sections, $3.0 \mu \mathrm{m}$ thick, were cut on a Reichert-Jung Biocut, incubated for $30 \mathrm{~min}$ at $56^{\circ} \mathrm{C}$, dewaxed in xylene, rehydrated through a graded ethanol series and brought to distilled water. SJNNV was detected by a standard avidin-biotin-alkaline-phosphatase complex (ABC/AP) immunohistochemistry technique according to Grotmol et al. (1999).

Statistical analysis. Differences in mortality were tested for statistical significance by the chi-square contingency table test with the Yates' correction, assuming a binomial distribution of the data. The relative percent survival (RPS) values were calculated according to Amend (1982).

\section{RESULTS}

\section{Immunisation trials}

In both Atlantic halibut and turbot the level of specific antibodies against rT2 increased during the experiment. However, both high- and low-responding individuals occurred in both species (Fig. 2). At 12 to 16 wk post-immunisation, the levels of rT2-specific antibodies increased markedly in the halibut groups (Fig. 2A), whereas in the turbot groups the antibody levels increased more gradually (Fig. 2B). There were no significant effects from a second immunisation in either of the species. In both species the highest antibody levels were detected at the termination of the experiment (20 wk post-immunisation). Sera collected prior to the immunisation were not able to neutralise the SJNNV (Table 2), whereas sera from all groups sampled on the termination of the experiment showed neutralising capacity. However, non-responders were present in all groups.

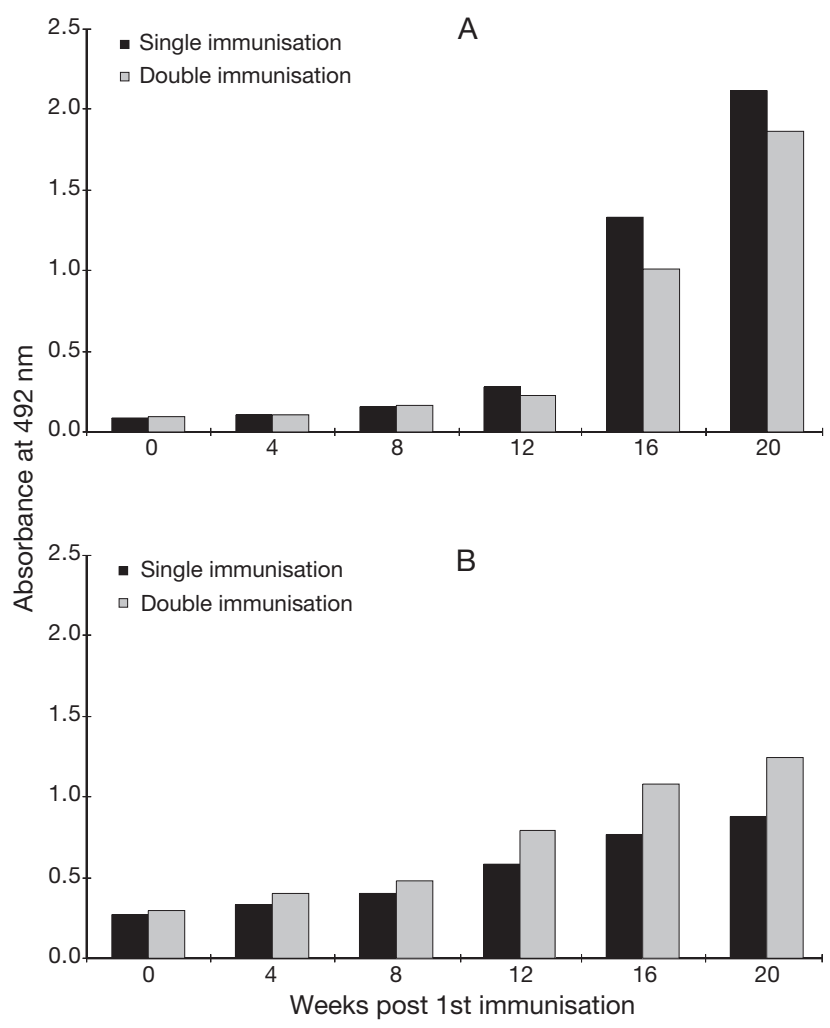

Fig. 2. Mean group antibody titres of rT2 immunised Atlantic halibut and turbot. Individual sera were sampled and measured by ELISA (absorbance at $492 \mathrm{~nm}$ ) using rT2 protein as coating antigen. (A) The immune response in Atlantic halibut immunised once $(\mathrm{N}=13)$ and twice $(\mathrm{N}=12)$. Samples were diluted 1:6400. (B) The immune response in turbot immunised once $(\mathrm{N}=14)$ and twice $(\mathrm{N}=14)$. Samples were diluted 1:400 
Table 2. Neutralising effect of sera from rT2 immunised Atlantic halibut and turbot. Individual sera were sampled 0 and $20 \mathrm{wk}$ post-immunisation. (A) Sera from Atlantic halibut immunised once $(N=11)$ and twice $(N=12)$. (B) Sera from turbot immunised once $(\mathrm{N}=13)$ and twice $(\mathrm{N}=11)$. Neutralising effect is expressed as the reciprocal value of the serum dilution that gives $50 \%$ or higher reduction of the SJNNV titre. 0: Serum dilution $<100$

\begin{tabular}{|c|c|c|c|c|}
\hline \multirow[t]{2}{*}{ Group } & \multicolumn{2}{|c|}{$\begin{array}{c}\text { Single } \\
\text { immunisation }\end{array}$} & \multicolumn{2}{|c|}{$\begin{array}{c}\text { Double } \\
\text { immunisation }\end{array}$} \\
\hline & $0 \mathrm{wk}$ & $20 \mathrm{wk}$ & $0 \mathrm{wk}$ & $20 \mathrm{wk}$ \\
\hline \multirow[t]{12}{*}{ (A) Atlantic halibut } & 0 & 0 & 0 & 0 \\
\hline & 0 & 100 & 0 & 0 \\
\hline & 0 & 100 & 0 & 0 \\
\hline & 0 & 1600 & 0 & 0 \\
\hline & 0 & 3200 & 0 & 0 \\
\hline & 0 & 3200 & 0 & 400 \\
\hline & 0 & 3200 & 0 & 800 \\
\hline & 0 & 6400 & 0 & 1600 \\
\hline & 0 & 6400 & 0 & 1600 \\
\hline & 0 & 6400 & 0 & 3200 \\
\hline & 0 & 6400 & 0 & 3200 \\
\hline & & & 0 & 3200 \\
\hline Mean & 0 & 3364 & 0 & 1167 \\
\hline \multirow[t]{13}{*}{ (B) Turbot } & 0 & 0 & 0 & 0 \\
\hline & 0 & 0 & 0 & 0 \\
\hline & 0 & 0 & 0 & 0 \\
\hline & 0 & 0 & 0 & 200 \\
\hline & 0 & 0 & 0 & 400 \\
\hline & 0 & 0 & 0 & 400 \\
\hline & 0 & 100 & 0 & 400 \\
\hline & 0 & 200 & 0 & 400 \\
\hline & 0 & 200 & 0 & 1600 \\
\hline & 0 & 1600 & 0 & 1600 \\
\hline & 0 & 1600 & 0 & 3200 \\
\hline & 0 & 3200 & & \\
\hline & 0 & 6400 & & \\
\hline Mean & 0 & 1023 & 0 & 745 \\
\hline
\end{tabular}

\section{Challenge trials with turbot}

\section{Clinical signs}

In Trial I, clinical signs were observed from Day 5 post-challenge and onwards in the infected groups kept at $21^{\circ} \mathrm{C}$ (IM 21-1, IM 21-2), and from d 8 postchallenge in the infected groups kept at $18^{\circ} \mathrm{C}$ (IM 18-1, IM 18-2). The initial symptoms were lethargy and loss of appetite, and apparently, all fish had these symptoms. A day later, clinical signs included darker coloration, hyperreactivity, abnormal swimming (uncoordinated darting, rolling and pitching) and hyperaemia around the cranium. On d 16 to 17 post-challenge most of the surviving fish at both temperatures had regained normal behaviour. No abnormal behaviour was recorded in the control groups (C 18, C 21).
In Trial II the groups challenged by intramuscular injection showed the same clinical signs as described above from Day 2 post-challenge. No clinical signs were observed in the bath-exposed groups.

\section{Mortality}

In Trial I, a significant raise in the mortality rate of both intramuscularly inoculated groups kept at $21^{\circ} \mathrm{C}$ was observed from Day 6 post-challenge (Fig. 3A). In the 2 intramuscularly inoculated groups kept at $18^{\circ} \mathrm{C}$, the raise in mortality started on Day 9 post-challenge. The cumulative mortality curves followed a sigmoid

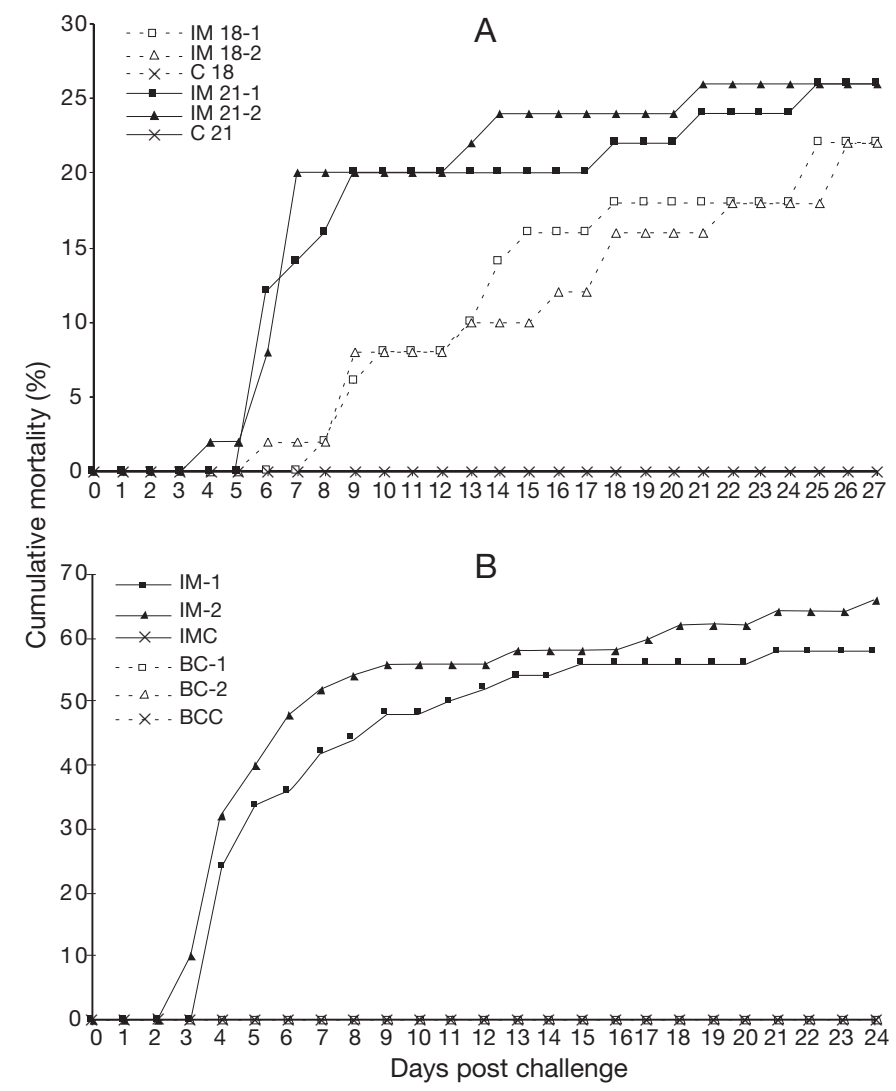

Fig. 3. Cumulative mortality curves of challenge Trials I and II on turbot. (A) Cumulative mortality curve of Trial I. The turbot were inoculated with $100 \mu \mathrm{l}$ SSN-1 cell line supernatant with a SJNNV titre of $1.0 \times 10^{7} \mathrm{TCID}_{50} \mathrm{ml}^{-1}$ and parallel groups were kept at $18^{\circ} \mathrm{C}$ (IM 18-1, IM 18-2) or $21^{\circ} \mathrm{C}$ (IM 21-1, IM 21-2). The mock-challenged groups are denoted $\mathrm{C} 18$ and C 21. (B) Cumulative mortality curve of Trial II, in which all groups were kept at $21^{\circ} \mathrm{C}$. Two groups of turbot (IM-1, IM-2) were inoculated with $100 \mu \mathrm{l} \mathrm{SSN-1}$ cell line supernatant with a SJNNV titre of $6.3 \times 10^{7} \mathrm{TCID}_{50} \mathrm{ml}^{-1}$ and 1 group was intramuscularly mock challenged (IMC). Two parallel groups were bath challenged (BC-1 and BC-2) for $1 \mathrm{~h}$ in seawater which had SJNNV added to a final titre of $3.7 \times 10^{7} \mathrm{TCID}_{50}$ $\mathrm{ml}^{-1}$. One group was mock bath challenged (BCC). Note that no mortality occurred in the bath-challenged groups 
pattern, and by Day 15 the mortality rates were declining. At the termination of the experiment, the cumulative mortality had reached 22 and $26 \%$ for the groups kept at 18 and $21^{\circ} \mathrm{C}$, respectively. No mortality occurred in the control groups during the experiment.

In Trial II, the onset of mortality in the intramuscularly inoculated groups (IM-1, IM-2) occurred on Days 3 and 4, and by Day 24 cumulative mortality had reached maxima of 58 and $66 \%$, respectively (Fig. 3B). No mortality was observed in the bath-exposed group or the control groups.

\section{Virus detection by RT-PCR}

All samples of eyes and abdominal organs from challenged fish in both trials were positive, whereas samples from the control fish were negative.

\section{Immunohistochemistry}

Specific immunolabelling was detected in the eyes, brains and spinal cords of all challenged fish. In intramuscularly inoculated fish from both trials that died during the acute stage of the infection, diffuse immunolabelled lesions in most parts of the brain and spinal cord were observed (Figs. 4 \& 6). In some of these fish ependymal cells of the choroid plexa were immunolabelled (Fig. 6). The brains and meninges were hyperaemic (Figs. $5 \& 6$ ). In the retina, lesions characterised by degeneration and vacuolation were preferentially located in a region of the bipolar and ganglionic layers adjacent to the growth zone at the ora serrata (Fig. 7). Samples from surviving intramuscularly inoculated fish had multifocal lesions, preferentially located in the brain stem, in the cranial spinal cord and in the retina adjacent to the ora serrata (Figs. 7, 8 \& 9). The multifocal lesion in the brain stem showed a pattern of distribution and occurred at anatomical locations characterised by clusters of neurones that probably represented nuclei of the caudal cranial nerves. In the spinal cord, the multifocal lesions were distributed segmentally (approximately 1 to each vertebra) in the grey matter of the ventral horn (Fig. 9). Immunolabelling was also observed in cells of the melano-macrophage centres in the kidneys of the surviving fish from all challenged groups (Fig. 10). This labelling was not found in fish that died during the acute stage of the challenges.

Bath-exposed turbot sampled on Day 14 post-challenge exhibited single-cell lesions that were diffusely scattered with no apparent pattern (Fig. 11). Fish from this group, sampled on Day 42 postchallenge, had less severe lesions. All these fish, however, had focal or single-cell lesions in the retinas, while a few focal or single-cell lesions were found in the CNS of approximately $50 \%$ of the samples.

\section{Reisolation of virus}

Except for fish from the unchallenged control groups, SJNNV was reisolated from all groups.

\section{Vaccine efficacy test on turbot}

Mortality and vaccine efficacy

No mortality was recorded in the period following vaccination until challenge was performed. The initial mortality was observed on Days 4 to 5 post-challenge in all SJNNV inoculated groups in both experiments. Following challenge at 5 wk post-vaccination, the mortality in the rT2-vaccinated group $\left(\mathrm{A}_{1}\right)$ was higher $(32 \%)$ than the mortality in the control-vaccinated group $\left(\mathrm{B}_{1}, 24 \%\right)$ (Table 3$)$. The mortality in the unvaccinated group $\left(\mathrm{C}_{1}, 48 \%\right)$ was higher compared to both the rT2-vaccinated $\left(A_{1}\right)$ and control-vaccinated $\left(B_{1}\right)$ groups. Challenge at $10 \mathrm{wk}$ post-vaccination resulted in significantly lower mortality in the rT2-vaccinated group $\left(\mathrm{A}_{2}, 8 \%\right)$ compared to the corresponding group challenged at 5 wk post-vaccination $\left(\mathrm{A}_{1}, 32 \%\right)$. Mortality rates in the control-vaccinated group $\left(B_{2}, 20 \%\right)$ and in the unvaccinated group $\left(\mathrm{C}_{2}, 44 \%\right)$ were similar to those observed in the equivalent groups $\left(\mathrm{B}_{1}\right.$ and $\left.\mathrm{C}_{1}\right)$ challenged at $5 \mathrm{wk}$ post-vaccination. When challenged 10 wk post-vaccination, both the rT2-vaccinated group $\left(A_{2}\right)$ and the control-vaccinated group $\left(B_{2}\right)$ showed sig-

Table 3. Vaccine efficacy test. Proportion of dead fish, \% cumulative mortality, relative percent survival (RPS) values and p-values $\left(\chi^{2}\right.$ test) on Day 18 post-challenge from tests performed 5 and $10 \mathrm{wk}$ post-vaccination (wpv). Significant differences ( $5 \%$ level) compared to the corresponding unvaccinated group are indicated by *

\begin{tabular}{|lcccc|}
\hline Time of challenge & Dead/total & \% mortality & RPS & p-value \\
\hline $\mathbf{5}$ wpv & & & & \\
rT2-vaccinated $\left(\mathrm{A}_{1}\right)$ & $16 / 50$ & 32 & 33 & 0.1530 \\
Control-vacinated $\left(\mathrm{B}_{1}\right)$ & $12 / 50$ & 24 & 50 & $0.0219^{*}$ \\
Unvaccinated $\left(\mathrm{C}_{1}\right)$ & $24 / 50$ & 48 & - & - \\
& & & & \\
$\mathbf{1 0}$ wpv & $4 / 50$ & 8 & 82 & $0.0001^{*}$ \\
rT2-vaccinated $\left(\mathrm{A}_{2}\right)$ & $10 / 50$ & 20 & 55 & $0.0184^{*}$ \\
Control-vaccinated $\left(\mathrm{B}_{2}\right)$ & $22 / 50$ & 44 & - & - \\
Unvaccinated $\left(\mathrm{C}_{2}\right)$ & & & & \\
\hline
\end{tabular}



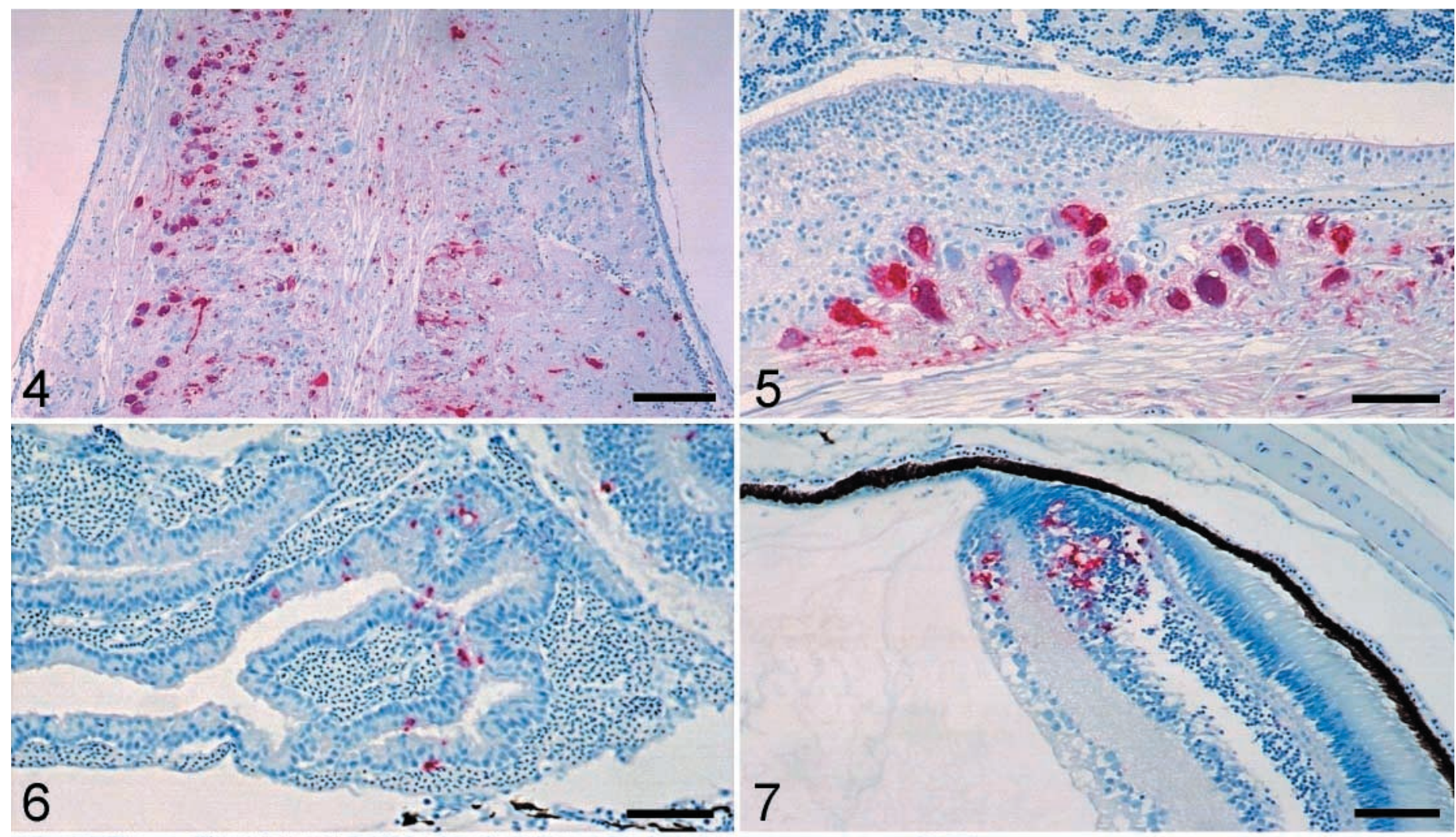

6

(1)

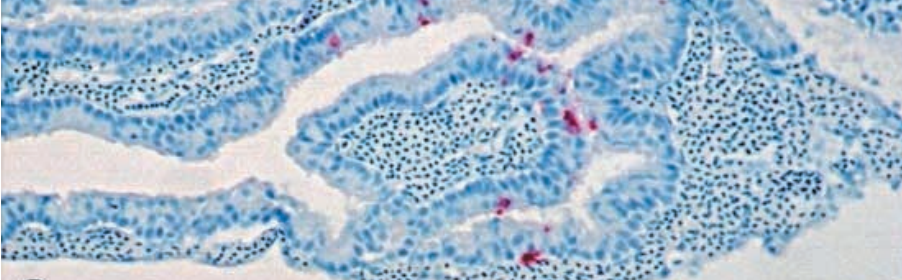
4.

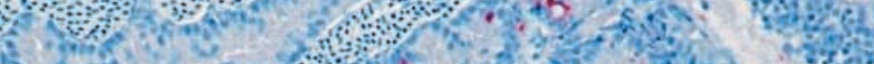

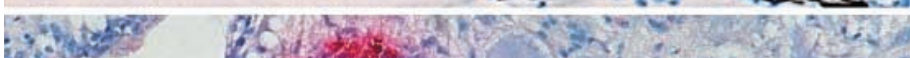

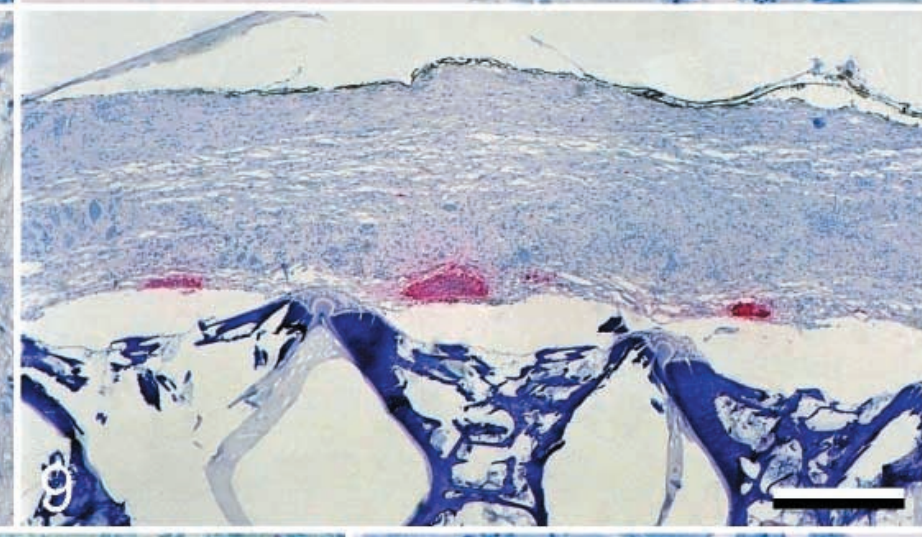

8 2. Wor

(1) He: 20
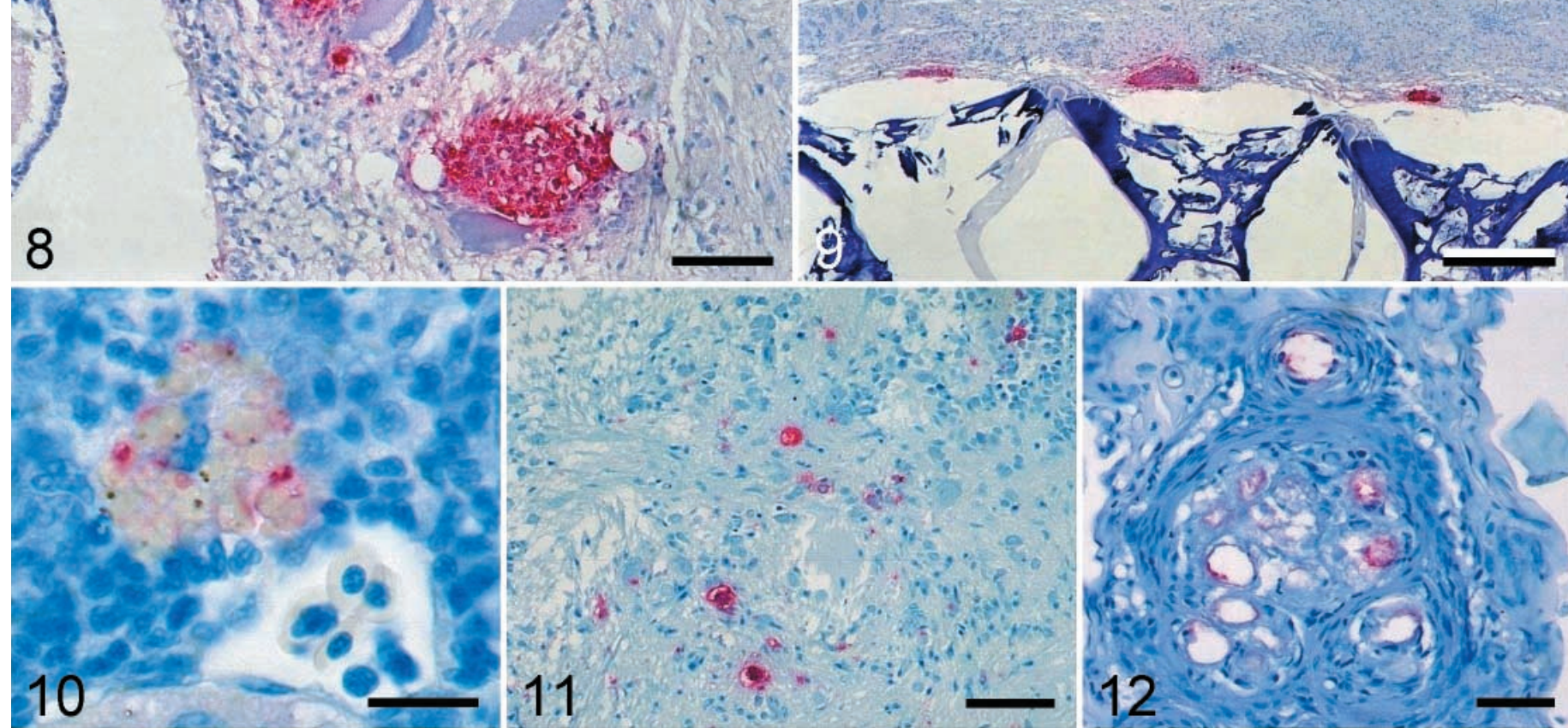
Figs. 4 to 12. Scophthalmus maximus. Immunohistochemical staining of paraffin sections. Avidin biotin alkaline phosphatase method, anti-rT2 rabbit serum and Mayers Haematoxylin counterstain. Fig. 4. Cranial spinal cord and brain stem. Intramuscularly inoculated fish that died $6 \mathrm{~d}$ post-challenge. Diffuse lesion. Scale bar $=40 \mu \mathrm{m}$. Fig. 5. Dorsal brain stem. Moribund fish intramuscularly inoculated. Note the pronounced immunolabelling in a group of large neurones and the dilated blood vessels packed with erythrocytes (hyperaemia). Scale bar $=20 \mu \mathrm{m}$. Fig. 6. Choroid plexus of brain. Moribund fish intramuscularly inoculated. Note the presence of immunolabelled ependymal cells and the dilated blood sinuses packed with erythrocytes (hyperaemia). Scale bar $=20 \mu \mathrm{m}$. Fig. 7. Retina. Fish surviving intramuscular inoculation. Note the immunolabelled lesion adjacent to the growth zone at the ora serrata. Closely similar lesions were observed in fish that died during the acute stage of the infection. Scale bar $=20 \mu \mathrm{m}$. Fig. 8. Brain stem. Fish that survived intramuscular inoculation. Two focal lesions are located in a nucleus containing large neurones. Scale bar $=20 \mu \mathrm{m}$. Fig. 9. Spinal cord. Fish that survived intramuscular inoculation. Segmental focal lesions are located in the ventral grey matter, one adjacent to each vertebra. Scale bar $=100 \mu m$. Fig. 10. Kidney. Intramuscularly inoculated surviving fish. Note immunolabelled cells within the melanomacrophage centre. Scale bar $=4 \mu \mathrm{m}$. Fig. 11 . Brain. Mesencephalon of bath-challenged fish sampled on Day 14 post-challenge. Immunolabelled single cells. Scale bar $=20 \mu m$. Fig. 12 . Visceral peritoneum. Fish vaccinated with rT2. Granulomas with centrally located immunolabelled vaccine droplets. Scale bar $=10$ um

nificantly different RPS values compared to unvaccinated fish (Table 3). No mortality was recorded in the unchallenged/unvaccinated control groups $\left(\mathrm{D}_{1}\right.$ and $\left.\mathrm{D}_{2}\right)$.

\section{Clinical signs}

No abnormal behaviour or lack of appetite was recorded in the period after vaccination until challenge was performed. The clinical signs were very similar in the control-vaccinated groups (B) and in the unvaccinated groups (C) in both challenge tests. Loss of appetite and hyperreaction were recorded from Day 4 post-challenge and onwards, and $2 \mathrm{~d}$ thereafter the fish showed all the characteristic clinical signs of VER. The fish of the rT2-vaccinated group $\left(\mathrm{A}_{1}\right)$ challenged 5 wk post-vaccination showed clinical signs identical to those of the control-vaccinated $\left(\mathrm{B}_{1}\right)$ and unvaccinated $\left(C_{1}\right)$ groups. The fish in the rT2-vaccinated group challenged $10 \mathrm{wk}$ post-vaccination $\left(\mathrm{A}_{2}\right)$ lost their appetite on Day 4 post-challenge, but no typical neurological symptoms such as hyperreactivity could be observed. On Day 6 post-challenge, these fish had regained appetite. The fish that died in this group, died before the normal onset of neurological symptoms. In the unchallenged/unvaccinated control groups (D), no clinical signs were recorded.

\section{Virus detection by RT-PCR}

All eye and brain samples from fish of the challenged groups were positive, while samples from control fish were negative.

\section{Immunohistochemistry}

Multifocal immunolabelled lesions characterised by neuronal degeneration and vacuolation were detected in all challenged groups (surviving fish sampled on Days 18 and 42 post-challenge). These lesions were preferentially located in the grey matter of the cranial spinal cord and brain stem (Figs. 8 \& 9), whereas in the retina, single positive cells were found in the bipolar nuclear and ganglion layers adjacent to the ora serrata (Fig. 7). All fish examined in the rT2-vaccinated (A), in the control-vaccinated (B) and unvaccinated (C) groups showed lesions in the CNS. However, in the retinas only $50 \%$ of the fish in the rT2-vaccinated group had immunolabelled cells, while all examined retinas from fish of the control-vaccinated (B) and of the unvaccinated (C) groups were affected. Mononuclear inflammatory cells could be observed in the posterior chamber of the eyes of most fish (not shown), but in the rT2-vaccinated (A) groups, inflammatory cells were only observed in a few specimens. Moderate amounts of granulomatous tissue were found in the peritoneum of all examined fish from the rT2-vaccinated groups (A) (Fig. 12) and in some of the fish from the control-vaccinated groups (B). Vacuoles that probably represented vaccine oil droplets could be observed in the centre of the granulomas, and immunolabelling within some vacuoles demonstrated the presence of rT2 remains (Fig. 12). No lesions were observed in the visceral organs. No obvious differences in the severity of the lesions were observed between the different groups or between sampling dates. Immunolabelling was not found in fish of the control groups (D).

\section{DISCUSSION}

\section{Immunisation trials}

The test vaccine containing the recombinant $\mathrm{T} 2$ protein (rT2) induced a specific humoral immune response with virus neutralising ability in both turbot and Atlantic halibut. This is in accordance with the findings 
of Nakai et al. (1995), who also detected SJNNVspecific antibodies in adult striped jack after immunisation with a recombinant capsid protein of SJNNV. In the present study, the antibody levels increased with time indicating a possible long-term effect. The lack of an additional quantitative antibody response in the fish that were immunised twice may be caused by the oil adjuvant permitting vaccine droplets to persist in the peritoneal cavity as a depot, providing long-term release of the antigen even after 1 administration (Catty \& Raykundalia 1988).

\section{Challenge trials on turbot}

Our study has demonstrated that turbot are susceptible to SJNNV and that they develop VER with significant mortality after intramuscular inoculation of nodavirus propagated in cell culture. Neuroinvasiveness of SJNNV was also found after bath exposure, although no clinical signs or mortality were recorded. In both challenge modes, the infection was verified by immunohistochemistry, RT-PCR and reisolation of SJNNV in cell culture. Even though bath exposure did not cause mortality, the present challenge model may be employed for studies of pathogenesis, for pathogenicity tests on different nodavirus strains and to test vaccine efficacy by measuring cumulative mortality.

Nodavirus strains affecting the turbot were not available when our study was initiated, and we were not able to successfully propagate the nodavirus strain affecting the Atlantic halibut in the SSN-1 cell line. However, the SSN-1 cell line is highly permissive with a clear cytopathic effect to a nodavirus strain affecting European sea bass Dicentrarchus labrax (Frerich et al. 1996). As demonstrated in the present study, SSN-1 is also permissive to SJNNV, thus permitting simple procedures for virus propagation and titration. For this reason, SJNNV was selected as the challenge strain in the present study.

The fact that the SSN-1 cell line is persistently infected with a retrovirus (Frerichs et al. 1991) may influence the results of studies in which this cell line is used to produce the inoculum. The retrovirus was probably present in the supernatants used for nodavirus inoculation and for mock challenge in the present study and in a study performed on immunologically competent European sea bass (Péducasse et al. 1999). In the mock-challenged groups of both studies, no signs of disease or mortality were observed, supporting the view that the retrovirus affects neither the European sea bass nor the turbot. Furthermore, no clinical response was observed in striped snakehead after intraperitoneal injection of the retrovirus (Frerichs et al. 1993). It cannot be ruled out, however, that the retrovirus may influence the course of the nodavirus infection, and further studies should be performed to clarify this. By disregarding the possible presence of retrovirus in the inoculum, the challenge models employing nodavirus propagated in the SSN-1 cell line fulfil Koch's postulates.

In Trial II of our study the amount of nodavirus for intramuscular inoculation was approximately 6 times as high as in Trial I. A significant difference in cumulative mortality was observed between the trials, implying that the mortality of turbot challenged intramuscularly with SJNNV is dependent on the virus dose. A virus dose dependency on mortality has also been found in sevenband grouper Epinephelus septemfasciatus (Tanaka et al. 1998). The slight differences in the cumulative mortality and in the onset of clinical signs observed in the present study, in which the turbot were challenged by intramuscular inoculation at 18 and $21^{\circ} \mathrm{C}$, is difficult to evaluate. Although the observed differences were not statistically significant, the results may indicate that the severity of VER in turbot increases with a rise in water temperature. A similar temperature-dependent effect after challenge with nodavirus has been indicated in other species (Arimoto et al. 1994, Tanaka et al. 1998, Chi et al. 1999).

In the present study mortality was not recorded in turbot after bath exposure to SJNNV, even though a high virus titre was employed. Similar results were obtained in redspotted grouper Epinephelus akaara that were bath challenged with a nodavirus strain from sevenband grouper. No mortality was recorded but some fish showed symptoms of VER (Tanaka et al. 1998). In contrast, European sea bass bath challenged with a nodavirus isolate from the sea bass (500 $\mathrm{pfu} \mathrm{m}^{-1}$ ) experienced $32 \%$ mortality (Péducasse et al. 1999). Furthermore, in both these studies the nodavirus could be detected in the CNS or retinas of most of the bathchallenged fish, which is in agreement with the results of our study. Differences in pathogenicity among nodavirus strains have been demonstrated (Totland et al. 1999) and the above observations may imply that the neurovirulence of different nodavirus strains to some degree is host specific and that high mortality may only be induced by intramuscular injection with high nodavirus titres in non-natural host species. Alternatively, the size or the developmental stage of the fish may influence the progression of infection after bath challenge. The latter notion is supported by the results of pathogenicity tests with SJNNV performed by bathexposing both larval and juvenile striped jack (Arimoto et al. 1993). In this study, SJNNV was highly pathogenic to larvae, whereas juveniles were not susceptible.

The results of the immunohistochemical examinations in the present study demonstrate a difference in the distribution pattern of lesions between fish that 
suffered an acute fatal infection and those that survived. In the fish that died, high neurovirulence with diffuse lesions affecting the retinas and most regions of the CNS was observed. SJNNV was detected in the CNS in all the survivors examined, demonstrating the potent neuroinvasiveness of the nodavirus. These results indicate that host defence mechanisms controlling the spread of nodavirus within the CNS (neurovirulence) may be crucial for survival. In the surviving fish, the immunolabelled multifocal lesions were preferentially located in the brain stem and cranial part of the spinal cord. Furthermore, the multifocal lesions seem to be associated with the nuclei of the caudal cranial nerves and regions containing segmentally distributed motor neurones throughout the ventral horn of the spinal cord. These foci may represent portals of entry into the CNS, and SJNNV may have reached them by retrograde axonal transport through motor nerves from inoculated musculature. If nodavirus, after intramuscular inoculation, enter the spinal cord and caudal brainstem by the above-mentioned routes, this could explain the differences in mortality observed in European sea bass after intraperitoneal and intramuscular inoculation of nodavirus (Péducasse et al. 1999). Intraperitoneal administration may result in a lower exposure to nerve components and putative viral receptor sites compared to intramuscular inoculation. It cannot be ruled out, however, that nerves associated with other tissues, to which the virus may have spread after inoculation, may offer alternative routes to the CNS. In addition, viral transport through the circulatory system may be of importance to the pathogenesis. In the bath-exposed groups of the present study, the lesions were not distributed in any apparent pattern, which implies that SJNNV may enter the CNS by other nerves or routes after bath challenge.

The immunolabelling of cells in the melanomacrophage centres of the kidney, observed in intramuscularly challenged turbot that survived infection, may reflect that nodavirus-antibody complexes, possibly present in the circulatory system, may have been entrapped by these cells in the venous sinuses of the kidney. Evidence of a possible mechanism whereby renal melanomacrophages are involved in the clearance of soluble circulating antigen-antibody complexes has been indicated (Espenes et al. 1996). Another possible explanation for our findings, although this is less likely, is that nodavirus may replicate in these cells. The presence of nodaviral antigens in renal tissue thus indicates that viremia may be induced after intramuscular inoculation.

Challenge trials with SJNNV on immunologically competent Atlantic halibut juveniles have been performed but no mortality was observed (S.G. unpubl. data). Since mortality was observed in turbot, this species was selected for vaccine efficacy tests.

\section{Vaccine efficacy test}

This study indicates that a test vaccine containing the rT2 protein provides protection in turbot when challenged with SJNNV 10 wk post-vaccination. Although SJNNV could be observed by immunohistochemistry in nervous tissue of all rT2-vaccinated fish after challenge, both the mortality and the severity of clinical signs were significantly reduced.

Following challenge at 5 wk post-vaccination, mortality in the rT2-vaccinated group was higher than in the control-vaccinated group. This may indicate that $5 \mathrm{wk}$ is insufficient to establish a protective vaccineinduced immune response, which is in accordance with the results of the immunisation trials on larger turbot of this study. Because mortality in the unvaccinated fish was higher than in either rT2-vaccinated or controlvaccinated fish, it is likely that the adjuvant by itself offers protection against challenge, possibly through non-specific stimulation of the immune system. This effect appears to last at least until $10 \mathrm{wk}$ post-vaccination, probably due to a slow release of adjuvant from depots.

As opposed to other modes of challenge, intramuscular inoculation has been shown both in our study and in others (Tanaka et al. 1998, Péducasse et al. 1999) to elicit more severe disease and higher mortality. Thus, vaccine efficacy tests for nodavirus employing intramuscular inoculation probably offer a strict evaluation of vaccine protection, and equivalent or better protection would be expected under field conditions.

Although a viral-neutralising humoral immune response may be triggered by a viral infection or by vaccination, the cellular component of the immune system is recognised as the major first line of defence against viral pathogens in naive individuals. The effect of nodavirus-neutralising antibodies on virus clearance or survival has not yet been elucidated. Furthermore, little is known about possible interactions between nodaviruses and the cellular immune system.

Since VER may cause high mortality in immunecompetent stages of several farmed marine teleost species, disease outbreaks may be controlled by vaccination. Further trials including other susceptible teleost species and other nodavirus strains are required in order to determine whether a vaccine containing an antigen from a particular virus strain such as SJNNV will offer general protection.

Acknowledgements. Dr T. Nakai (Hiroshima University, Japan) is thanked for supplying striped jack infected with SJNNV, and Dr T. Nishizawa (Hiroshima University, Japan) for his help in the cloning and production of the recombinant protein. We also thank H. Rudra, K. Glover, I. Uglenes, T. Boge Eriksen, H. Kongshaug, K. Gjul Gaustad and B. Spasowska for excellent technical assistance. This study was financed by Intervet Norbio AS, Bergen, Norway. 


\section{LITERATURE CITED}

Amend DF (1982) Potency testing of fish vaccines. In: Anderson DP, Hennessen H (eds) Fish biologics: serodiagnostics and vaccines. Dev Biol Stand. Basel, Karger 49:447-454

Arimoto M, Mori K, Nakai T, Muroga K, Furusawa I (1993) Pathogenicity of the causative agent of viral nervous necrosis disease in striped jack, Pseudocaranx dentex (Bloch and Schneider). J Fish Dis 16:461-469

Arimoto M, Maruyama K, Furusawa I (1994) Epizootiology of viral nervous necrosis (VNN) in striped jack. Fish Pathol 29:19-24

Bloch B, Gravningen K, Larsen JL (1991) Encephalomyelitis among turbot associated with a picornavirus-like agent. Dis Aquat Org 10:65-70

Catty D, Raykundalia C (1988) Polyclonal antibodies. In Catty D (ed) Antibodies, Vol 1, a practical approach. IRL Press, Oxford, p 22-23

Chi SC, Lin SC, Su HM, Hu WW (1999) Temperature effect on nervous necrosis virus infection in grouper cell line and in grouper larvae. Virus Res 63:107-114

Comps M, Pepin JF, Bonami JR (1994) Purification and characterization of two fish encephalitis virus (FEV) infecting Lates calcarifer and Dicentrarchus labrax. Aquaculture 123:1-10

Espenes A, McL Press C, Reitan LJ, Landsverk T (1996) The trapping of intravenously injected extracellular products from Aeromonas salmonicida in head kidney and spleen of vaccinated and nonvaccinated Atlantic salmon, Salmo salar L. Fish Shellfish Immunol 6:413-426

Frerichs GN, Morgan D, Heart D, Skerrow C, Roberts RJ, Onions D (1991) Spontaneously productive C-type retrovirus infection of fish cell lines. J Gen Virol 72: 2537-2539

Frerichs GN, Millar SD, Chinabut S (1993) Clinical response of snakeheads (Ophicephalus striatus) to experimental infection with sneakehead fish rhabdovirus and snakehead cell line retrovirus. Aquaculture 116:297-301

Frerichs GN, Rodger HD, Peric Z (1996) Cell culture isolation of piscine neuropathy nodavirus from juvenile sea bass, Dicentrarchus labrax. J Gen Virol 77:2067-2071

Fukuda Y, Nguyen HD, Furuhashi M, Nakai T (1996) Mass mortality of cultured sevenband grouper, Epinephelus septemfasciatus, associated with viral nervous necrosis. Fish Pathol 31:165-170

Grotmol S, Totland GK, Thorud K, Hjeltnes BK (1997) Vacuolating encephalopathy and retinopathy associated with a nodavirus-like agent: a probable cause of mass mortality of cultured larval and juvenile Atlantic halibut Hippoglossus hippoglossus. Dis Aquat Org 29:85-97

Grotmol S, Bergh Ø, Totland GK (1999) Transmission of viral encephalopathy and retinopathy (VER) to yolk-sac larvae of the Atlantic halibut Hippoglossus hippoglossus: occurrence of nodavirus in various organs and a possible route of infection. Dis Aquat Org 36:95-106

Grotmol S, Nerland AH, Biering E, Totland GK, Nishizawa T (2000) Characterisation of the capsid protein gene from a nodavirus strain affecting the Atlantic halibut Hippoglossus hippoglossus and design of an optimal reverse-transcriptase polymerase chain reaction (RT-PCR) detection assay. Dis Aquat Org 39:79-88

Knappskog DH, Sommer AI, Rødseth OM (1999) Efficacy testing of different vaccine formulations using a laboratory IPNV challenge model (immersion). In: Proceedings of The European Association of Fish Pathologists, 9th International Conference, 'Diseases of Fish and Shellfish', Rhodes, Greece, 19-24 Sept

Laemmli UK (1970) Cleavage of structural proteins during the assembly of the head of bacteriophage T4. Nature 227: 680-685

Le Breton A, Grisez L, Sweetman J, Ollevier F (1997) Viral nervous necrosis (VNN) associated with mass mortalities in cage-reared sea bass, Dicentrarchus labrax (L.). J Fish Dis 20:145-151

Leong JC, Fryer JL (1993) Viral vaccines for aquaculture. Annu Rev Fish Dis 3:225-240

Lorenzen N, Olesen NJ (1997) Immunization with viral haemorrhagic septicaemia antigens. In: Gudding R, Lillehaug A, Midtlyng PJ, Brown F (eds) Fish vaccinology. Dev Biol Stand 90:201-209

Mori K, Nakai T, Muroga K, Arimoto M, Mushiake K, Furusawa I (1992) Properties of a new virus belonging to Nodaviridae found in larval striped jack (Pseudocaranx dentex) with nervous necrosis. Virology 187:368-371

Munday BL, Nakai T (1997) Special topic review: nodaviruses as pathogens in larval and juvenile marine finfish. World $\mathrm{J}$ Microbiol Biotechnol 13:375-381

Mushiake K, Arimoto M, Furosawa T, Furosawa I, Nakai T, Muroga K (1993) Viral nervous necrosis virus (VNN) of striped jack: effects of plasma antibody level of spawners and spawning conditions on the occurrence of the disease in their offsprings. Suisanzoshoku 41:327-332

Mushiake KT, Nishizawa K, Nakai T, Furusawa I, Muroga K (1994) Control of VNN in striped jack: selection of spawners based on the detection of SJNNV gene by polymerase chain reaction (PCR). Fish Pathol 29:177-182

Nagai T, Nishizawa T (1999) Sequence of the non-structural protein gene encoded by RNA1 of striped jack nervous necrosis virus. J Gen Virol 80:3019-3022

Nakai T, Mori K, Arimoto M, Muroga K (1995) Neutralizing antibody production in striped jack immunized with a recombinant coat protein of striped jack nervous necrosis virus (SJNNV). In: Proceedings of The European Association of Fish Pathologists, Seventh International Conference, 'Diseases of Fish and Shellfish', Palma de Mallorca, 10-15 Sept

Nishizawa T, Mori K, Nakai T, Furusawa I, Muroga K (1994) Polymerase chain reaction (PCR) amplification of RNA of striped jack nervous necrosis virus (SJNNV). Dis Aquat Org 18:103-107

Nishizawa T, Mori $K$, Furuhashi M, Nakai T, Furusawa I, Muroga K (1995) Comparison of the coat protein genes of five fish nodaviruses, the causative agents of viral nervous necrosis in marine fish. J Gen Virol 76:1563-1569

Nishizawa T, Furuhashi M, Nagai T, Nakai T, Muroga K (1997) Genomic classification of fish nodaviruses by phylogenetic analysis of the coat protein gene. Appl Environ Microbiol 63(4):1633-1636

Péducasse S, Castric J, Thiéry R, Jeffroy J, Le Ven A, Baudin Laurencin F (1999) Comparative study of viral encephalopathy and retinopathy in juvenile sea bass Dicentrarchus labrax infected in different ways. Dis Aquat Org 36:11-20

Reed LJ, Muench H (1938) A simple method of estimating fifty percent end points. Am J Hyg 27:493-497

Tanaka S, Aoki H, Nakai T (1998) Pathogenicity of the nodavirus detected from diseased sevenband grouper Epinephelus septemfasciatus. Fish Pathol 33(1):31-36

Totland GK, Grotmol S, Morita Y, Nishioka T, Nakai T (1999) The pathogenicity of nodavirus strains from striped jack Pseudocaranx dentex and Atlantic halibut Hippoglossus hippoglossus studied by waterborne challenge of yolk-sac larvae of both teleost species. Dis Aquat Org 38:169-175

Yoshimizu M, Suzuki K, Nishizawa T, Winton JR, Ezura Y (1997) Antibody screening for the identification of nervous necrosis virus carriers in a flounder brood stock. Proc NRIA International Workshop 'New Approaches to Viral Diseases of Aquatic Animals', Kyoto, p 124-130

Submitted: May 12, 2000; Accepted: December 28, 2000 Proofs received from author(s): April 23, 2001 